\title{
The Successful Use of Desmopressin With Tranexamic Acid in Children With Mild Type 1 Von Willebrand Disease Who Undergo Circumcision
}

\author{
Hayri Elicabuk $^{\mathrm{a}}$, Halil Beydilli ${ }^{\mathrm{b}}$ e, Mehmet Akin ${ }^{\mathrm{c}}$, Mustafa Serinken ${ }^{\mathrm{d}}$
}

\begin{abstract}
Background: Desmopressin (DDAVP) is a synthetic vasopressin analog, and increases endogenous von Willebrand factor (VWF) by secreting it from the vascular endothelial cell. Circumcision is one of the oldest and most commonly performed operations in the world. This study reported the specific uses of DDAVP together with tranexamic acid in children with mild type 1 von Willebrand disease (VWD) undergoing circumcision. The aim of this study was to report the successful use of DDAVP in two doses and tranexamic acid in six children with VWD undergoing circumcision.
\end{abstract}

Methods: Our study evaluated two doses of DDAVP therapy in circumcision operation of six male children diagnosed with mild type 1 VWD with a good response to DDAVP before they underwent circumcision, with a mean age of 7.3 years. The subcutaneous preparation of DDAVP was utilized. Under medical supervision, patients were subcutaneously injected DDAVP at a dose between 0.3 and 0.2 $\mu \mathrm{g} / \mathrm{kg}$ based on their weight. Oral tranexamic acid was instituted at a dosage of $15 \mathrm{mg} / \mathrm{kg}$ three times per day for 5 days. The first dose was given 24 hours before circumcision. The first and second doses of DDAVP were given 1 hour before the circumcision and 24 hours after the circumcision, respectively.

Results: This study included six male children aged 4 - 10 years with mild type $1 \mathrm{VWD}$, weighting 22 - $30 \mathrm{~kg}$. The DDAVP dose (mean, range) based on the patient's weight was $0.25(0.23-0.28 \mu \mathrm{g} / \mathrm{kg})$. The calculated dose was repeated two times for each patient. Laboratory values (mean, range, U/dL) of baseline VWF:Ag, VWF:RCo and FVIII:C in mild type 1 VWD patients were 37 (32 - 42), 38 (34 - 42), and 50 (44 - 56), respectively.

Manuscript accepted for publication October 15, 2015

aDepartment of Emergency Medicine, Servergazi State Hospital, Turkey ${ }^{b}$ Department of Emergency Medicine, Mugla University Medical Faculty, Turkey

'Department of Pediatric Hematology, Pamukkale University Medical Faculty, Turkey

${ }^{\mathrm{d} D e p a r t m e n t ~ o f ~ E m e r g e n c y ~ M e d i c i n e, ~ P a m u k k a l e ~ U n i v e r s i t y ~ M e d i c a l ~ F a c u l t y, ~}$ Turkey

${ }^{\mathrm{e}}$ Corresponding Author: Halil Beydilli, Department of Emergency Medicine, Mugla University Medical Faculty, Turkey. Email: hbeydilli@hotmail.com

doi: http://dx.doi.org/10.14740/ijcp228e
Conclusion: Single infusions of DDAVP for common bleeding episodes do not usually require laboratory monitoring. There are limited published data to guide clinical practice about the optimal dosing and timing of these agents to prevent or resolve bleeding using DDAVP at minor surgeries as circumcision operation. Castaman et al showed almost all minor surgeries and deliveries occurring during followup were successfully managed with DDAVP in patients with type 1 VWD. We used two doses in circumcision like O'Brein. Comparison of the results across studies is difficult, as surgical techniques, timing, and frequency of DDAVP dosing, and use and dosing of antifibrinolytics all varied by institution. Two doses of DDAVP allowed adequate perioperative bleeding prophylaxis management in children with mild type 1 VWD who underwent circumcision surgery with presenting bleeding complications.

Keywords: VWD; Desmopressin; Circumcision

\section{Introduction}

Desmopressin (DDAVP) is the treatment of choice for the majority of patients with type 1 von Willebrand disease (VWD). DDAVP (1-desamino-8-D-arginine vasopressin), a synthetic vasopressin analog, increases endogenous von Willebrand factor (VWF) by secreting it from the vascular endothelial cell, its natural site of synthesis and storage [1]. The severity of the bleeding tendency is usually proportional to the degree of the VWF defect, although the large majority of cases diagnosed appear to have mild disease. DDAVP is usually effective in patients with type 1 and baseline VWF and FVIII levels higher than $10 \mathrm{IU} / \mathrm{dL}$. The intravenous or subcutaneous dose is 0.2 $-0.3 \mu \mathrm{g} / \mathrm{kg}$. Treatment can be repeated every $12-24 \mathrm{~h}$ depending on the type and severity of the bleeding $[2,3]$.

Circumcision is one of the oldest and most commonly performed operations in the world. It is a religious covenant for Jewish males and was recommended by the Muslims' prophet Mohammed to his society [4]. Although its life-threatening effect for VWD is well described and it is only a recommendation for Muslims in Turkey, their families consider that circumcision is a very important step to become a member of society and it is a social obligation for men [5].

In the current literature, limited data regarding DDAVP management of circumcision in mild type 1 VWD are available. 


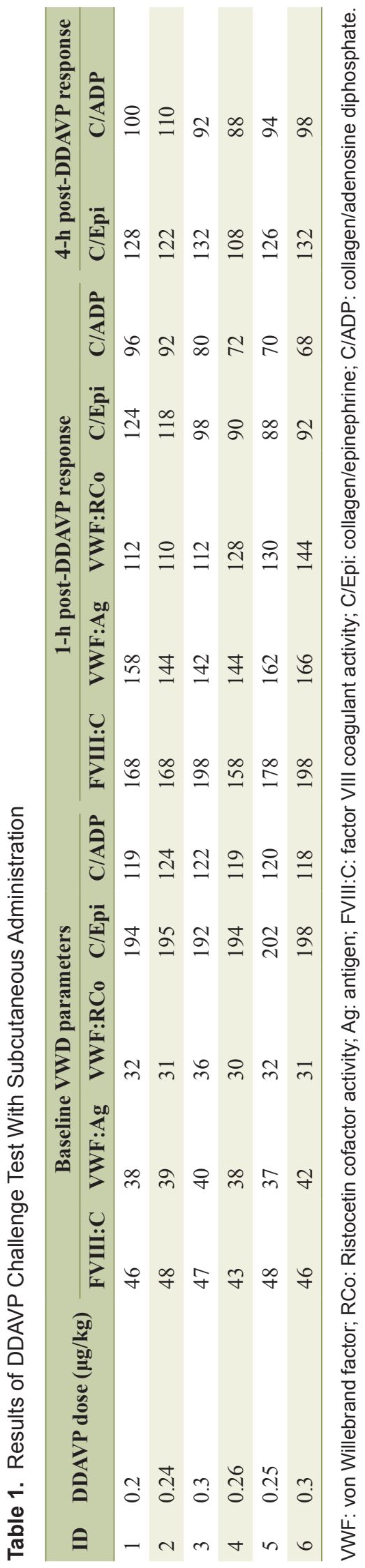

The aim of this study was to report the successful use of DDAVP in two doses and tranexamic acid in six children with VWD undergoing circumcision.

\section{Patients and Methods}

Our study evaluated two doses of DDAVP therapy during circumcision operation of six male children, whose mean age was 7.3 (4 - 10) years, diagnosed with mild type 1 VWD with a good response to DDAVP treatment before they underwent circumcision [6]. It was a prospective blind observational study. Ethics Board approval and parents' informed consent were received. The study was undertaken in Pamukkale University. The most common bleeding symptoms were epistaxis (100\%) and bruising $(50 \%)$. Criteria for the diagnosis of mild type 1 VWD were von Willebrand factor antigen (VWF:Ag), von Willebrand factor ristocetin cofactor (VWF:RCo) levels between 31 and $49 \mathrm{IU} /$ $\mathrm{dL}$ and disproportionately low ratio of VWF:RCo to VWF:Ag (VWF:RCo/VWF:Ag > 0.7), and at least one bleeding symptom.

The subcutaneous preparation of DDAVP $(4 \mu \mathrm{g} / \mathrm{mL}$; Mini$\operatorname{rin}^{\circledR}$, Ferring, Kiel, Germany) was utilized. Under medical supervision, patients were subcutaneously injected DDAVP between at a dose of 0.3 to $0.2 \mu \mathrm{g} / \mathrm{kg}$ based on their weight. Oral tranexamic acid was instituted at a dosage of $15 \mathrm{mg} / \mathrm{kg}$ three times per day for 5 days. The first dose was given $24 \mathrm{~h}$ before circumcision.

The first and second doses of DDAVP were given $1 \mathrm{~h}$ before the circumcision and $24 \mathrm{~h}$ after the circumcision, respectively. No measurement for plasma factor level was done. Circumcision was carried out under general anesthesia. The prepuce was incised circumferentially and excised using Gomco clamp or open technique.

Patients were discharged $24 \mathrm{~h}$ after circumcision and they had not any type of bleeding complication in subsequent week.

\section{Results}

This study included six male children aged 4 - 10 years with mild type $1 \mathrm{VWD}$, weighting $22-30 \mathrm{~kg}$. The DDAVP dose (mean, range) based on the patient's weight was 0.25 (0.23 $0.28 \mu \mathrm{g} / \mathrm{kg}$ ). The calculated dose was repeated two times for each patient.

Laboratory values (mean, range, U/dL) of baseline VWF:Ag, VWF:RCo and FVIII:C in mild type 1 VWD patients were 37 (32 - 42), 38 (34 - 42), and 50 (44 - 56), respectively. All the mild type 1 VWD patients achieved initial and sustained response (VWF:RCo levels $>40 \%$ for a minimum of $1 \mathrm{~h}$ and normal PFA-100 CT for $4 \mathrm{~h}$ to DDAVP delivered by a subcutaneous route in Table 1) [7, 8].

In the period of 5 days after circumcision, bleeding was no observed in any patient.

\section{Discussion}

Circumcision is a very important ritual for Muslim and Jewish 
populations. Almost all parents of patients with VWD are willing to have their children circumcised.

Short-term DDAVP prophylaxis was successfully applied ranging from $91 \%$ to $100 \%$ to prevent excessive bleeding following surgery or invasive procedures in patients with type 1 VWD $[9,10]$. In our study, clinical responses were excellent with no bleeding episode.

Single infusions of DDAVP for common bleeding episodes such as epistaxis, simple dental extraction or menorrhagia do not usually require laboratory monitoring [11]. There are limited published data to guide clinical practice about the optimal dosing and timing of these agents to prevent or resolve bleeding using DDAVP at minor surgeries as circumcision operation. Castaman et al showed almost all dental extractions, minor surgeries and deliveries occurring during follow-up were successfully managed with DDAVP in patients with type 1 VWD [12].

Previous studies showed that patients with mild/moderate type 1 VWD undergoing an adenotonsillar procedure were treated with the same hemostatic regimen consisting of one single dose of DDAVP and an extended use of antifibrinolytic therapy [13-15]. Due to the prolonged risk period of postoperative bleeding with tonsillectomy, O'Brein recommended to use DDAVP preoperatively and $24 \mathrm{~h}$ after surgery [16].

We used two doses in circumcision like O'Brein. Comparison of the results across studies is difficult, as surgical techniques, timing, and frequency of DDAVP dosing, and use and dosing of antifibrinolytics all varied by institution.

In conclusion, the two doses of DDAVP allowed adequate perioperative bleeding prophylaxis management in children with mild type 1 VWD who undergo circumcision surgery with presenting bleeding complications.

\section{References}

1. Mannucci PM, Bettega D, Cattaneo M. Patterns of development of tachyphylaxis in patients with haemophilia and von Willebrand disease after repeated doses of desmopressin (DDAVP). Br J Haematol. 1992;82(1):87-93.

2. Mannucci PM, Franchini M, Castaman G, Federici AB. Evidence-based recommendations on the treatment of von Willebrand disease in Italy. Blood Transfus. 2009;7(2):117-126.

3. Federici AB. Prophylaxis of bleeding episodes in patients with von Willebrand's disease. Blood Transfus. 2008;6(Suppl 2):s26-32.

4. Kavakli K, Aledort LM. Circumcision and haemophilia: a perspective. Haemophilia. 1998;4(1):1-3.

5. Yilmaz D, Akin M, Ay Y, Balkan C, Celik A, Ergun O,
Kavakli K. A single centre experience in circumcision of haemophilia patients: Izmir protocol. Haemophilia. 2010;16(6):888-891.

6. Akin M. Laboratory diagnostic approach of the parentschildren relationship in differentiating low-level von Willebrand factor from mild type 1 von Willebrand disease. Blood Coagul Fibrinolysis. 2012;23(4):351-353.

7. Akin M. Response to low-dose desmopressin by a subcutaneous route in children with type 1 von Willebrand disease. Hematology. 2013;18(2):115-118.

8. Akin M, Karapinar DY, Balkan C, Ay Y, Kavakli K. An evaluation of the DDAVP infusion test with PFA-100 and vWF activity assays to distinguish vWD types in children. Clin Appl Thromb Hemost. 2011;17(5):441-448.

9. Federici AB, Sacco R, Stabile F, Carpenedo M, Zingaro E, Mannucci PM. Optimising local therapy during oral surgery in patients with von Willebrand disease: effective results from a retrospective analysis of 63 cases. Haemophilia. 2000;6(2):71-77.

10. Nitu-Whalley IC, Griffioen A, Harrington C, Lee CA. Retrospective review of the management of elective surgery with desmopressin and clotting factor concentrates in patients with von Willebrand disease. Am J Hematol. 2001;66(4):280-284.

11. Nichols WL, Hultin MB, James AH, Manco-Johnson MJ, Montgomery RR, Ortel TL, Rick ME, et al. von Willebrand disease (VWD): evidence-based diagnosis and management guidelines, the National Heart, Lung, and Blood Institute (NHLBI) Expert Panel report (USA). Haemophilia. 2008;14(2):171-232.

12. Castaman G, Tosetto A, Federici AB, Rodeghiero F. Bleeding tendency and efficacy of anti-haemorrhagic treatments in patients with type 1 von Willebrand disease and increased von Willebrand factor clearance. Thromb Haemost. 2011;105(4):647-654.

13. Berlucchi M, Tomenzoli D, Nicolai P, Lusk RP. Adenotonsillectomy in children with von Willebrand's disease: how and when. A case report with review of the literature. Int J Pediatr Otorhinolaryngol. 2002;65(3):253-256.

14. Dunn AL, Cox Gill J. Adenotonsillectomy in patients with desmopressin responsive mild bleeding disorders: a review of the literature. Haemophilia. 2010;16(5):711-716.

15. Santoro C, Hsu F, Dimichele DM. Haemostasis prophylaxis using single dose desmopressin acetate and extended use epsilon aminocaproic acid for adenotonsillectomy in patients with type 1 von Willebrand disease. Haemophilia. 2012;18(2):200-204.

16. O'Brien SH. Common management issues in pediatric patients with mild bleeding disorders. Semin Thromb Hemost. 2012;38(7):720-726. 